Revista Iberoamericana. Vol. LXIII, Núm. 180, Julio-Setiembre 1997; 391-404

\title{
EL INTERTEXTO DE LA IMITACIÓN EN GARCILASO, GÓNGORA Y BALBUENA
}

\author{
POR \\ Gustavo V. García \\ University of Wisconsin-Madison
}

La crítica, en general, reconoce que la poesía del Siglo de Oro se nutrió de "novedades italianistas" (Blecua 9). Éstas eran numerosas y, de una u otra forma, influyeron en poetas peninsulares que muchas veces rechazaron la relación estrecha entre sus creaciones y las de sus modelos italianos. Tal actitud, observable en la sutileza de algunos poemas imitativos, hace difícil identificar sus fuentes que, por lo demás, no se reducen a una sola. La situación se complica cuando la imitatio $^{1}$ es practicada por autores que residían en las colonias americanas. En este caso, además de imitar a los españoles se imita también a los italianos. Así se establece una cadena de influencias no siempre armónica, debido a la aceptación entusiasta de unos y resistencia de otros:

Apenas el español pisa tierras americanas, transplanta el arte y la poesía del Renacimiento .... la España que nos descubre no es la medieval, sino la renacentista; y la poesía que los primeros poetas mexicanos reconocen como suya es la misma que en España se miraba como descastada y extranjera: la italiana (Paz, Las peras del olmo 3-4).

La imitatio establece relaciones de dependencia referencial de un texto respecto a otro ubicado en cierto período preciso. ${ }^{2}$ Sin embargo, cuando da origen a obras derivadas de una fuente común y, al mismo tiempo, "emparentadas" entre ellas, la intertextualidad ${ }^{3}$ se enriquece y complica generando opiniones críticas sesgadas. Por ejemplo, la identificación del arquetipo privilegiado o el pasar por alto eslabones claves para la comprensión de los textos imitativos.

\footnotetext{
'Imitatio es un concepto elástico. En este ensayo significa el proceso creativo en el que se imita uno o varios modelos. Para comprender su importancia en autores clásicos y renacentistas véase Pigman III, 1-32.

${ }^{2}$ En realidad no se puede hablar de una fuente "única" como origen de los textos que la imitan; ya que ésta, a su vez, hace referencia a otra anterior a ella. Claro que existen modelos privilegiados 0 , por lo menos, más visibles que otros. Cuando éste es el caso, la referencialidad imitativa puede establecerse con precisión aceptable.

${ }^{3}$ Intertextualidad, de acuerdo a Julia Kristeva, es el proceso en el que los textos se constituyen a través de actos de asimilación y/o modificación de obras previas. Cualquier escrito literario, en esta perspectiva, es la reelaboración de otro leído con anterioridad. Ver Le texte du roman y Sémiotiké, recherches pour une sémanalyse.
} 
El propósito de este ensayo es analizar la imitación e intertextualidad subyacentes en tres sonetos del Siglo de Oro. Los escritos en España, "En tanto que de rosa y azucena" de Garcilaso de la Vega ${ }^{4}$ y "Mientras por competir con tu cabello" de Luis de Góngora, ${ }^{5}$ son archiconocidos y han dado lugar a una profusa bibliografía. ${ }^{6}$ El elaborado en Nueva España, "Mientras que por la limpia y tersa frente" de Bernardo de Balbuena, ${ }^{7}$ ha tenido menos

${ }^{4}$ José Manuel Blecua suministra esta versión:

En tanto que de rosa y azucena se muestra la color en vuestro gesto, y que vuestro mirar ardiente, honesto, con clara luz la tempestad serena;

$y$ en tanto que el cabello, que en la vena

del oro se escogió, con vuelo presto, por el hermoso cuello blanco, enhiesto, el viento mueve, esparce y desordena; coged de vuestra alegre primavera el dulce fruto, antes que el tiempo airado cubra de nieve la hermosa cumbre.

Marchitará la rosa el viento helado, todo lo mudará la edad ligera por no hacer mudanza en su costumbre (Blecua 68).

${ }^{5} \mathrm{El}$ soneto gongorino es el siguiente:

Mientras por competir con tu cabello oro bruñido al sol relumbra en vano; mientras con menosprecio en medio el llano mira tu blanca frente el lilio bello; mientras a cada labio, por cogello, siguen más ojos que al clavel temprano, y mientras triunfa con desdén lozano del luciente cristal tu gentil cuello, goza cuello, cabello, labio y frente, antes que lo que fue en tu edad dorada oro, lilio, clavel, cristal luciente,

no sólo en plata o víola troncada se vuelva, mas tú y ello juntamente en tierra, en humo, en polvo, en sombra, en nada (Góngora 230).

' Véanse los trabajos de Alonso, Aznar, Calcraft, Carballo Picazo, Cruz, Gerli, Lapesa, Stanton, Terracini, etc.

${ }^{7}$ El soneto de Balbuena se publicó por primera vez en 1608 en su libro Siglo de oro en las selvas de Erifile:

Mientras que por la limpia y tersa frente ese cabello de oro ensortijado al fresco viento vuela marañado sobre las tiernas rosas del oriente; mientras la primavera está presente dese clavel, sobre marfil sentado: coged las flores y alegrias del prado, que el tiempo corre, huye y no se siente. ¿De qué fruto os será la hermosura cuando el invierno vista de su nieve la lumbre de oro y encarnadas rosas? 
fortuna. Aparte de una u otra referencia breve, y por lo general equivocada, no ha generado el interés académico que merece. ${ }^{8}$

En las composiciones de Garcilaso y Góngora, a las cuales habría que añadir la de Balbuena, la crítica alude a la presencia de tópicos similares. En efecto, las coincidencias resaltan de inmediato y su contenido argumental, en apariencia el mismo, es la exhortación a gozar de la belleza en el instante preciso de su manifestación máxima, la juventud. El paralelismo no es casual y sí intencional. Está inserto en el tópico del carpe diem horaciano" y en el del collige, virgo, rosas de Ausonio. Aunque la utilización de tales temas estaba muy extendida en bardos de la época, no es suficiente para explicar la similitud, en cuanto a estructura temática, de los poemas objeto de análisis. Para ello hace falta señalar una fuente común que los críticos ubican en un soneto escrito por Bernardo Tasso. ${ }^{10}$

Fernando de Herrera, uno de los primeros en analizar la poesía del Siglo de Oro indica que:

Garci Lasso ... si no me engaño, lo traduzio; i vean la ventaja que hizo el uno al otro en algunas cosas, porq[ue] - lo q[ue] yo siento-el 3 i el 4 verso de G.L. son incomparables; i también estremados el 7 i el $8 \mathrm{i}$, al contrario, los dos primeros del Tasso i el primer terceto son maravillosos, aunque los últimos de ambos no responden a lo que prometio el principio (Citado por Carballo Picazo 383).

Lapesa, defendiendo la originalidad relativa del castellano, hace referencia breve a otras fuentes posibles:

El soneto de nuestro poeta tiene disposición muy semejante al de Bernardo Tasso 'Mentre che l'aureo crin'ondeggia in torno', que además deja su huella en algunas imágenes; pero

Si la edad pasa, el tiempo la apresura;

las horas vuelan, y en su curso breve

hallan y tienen fin todas las cosas (Balbuena citado por Rojas Garcidueñas 102).

${ }^{8}$ El ensayo de Colombí-Monguió es una valiosa excepción.

${ }^{9}$ El tema del carpe diem horaciano, de acuerdo a Lapesa, "había resucitado, y desde Lorenzo de Médicis contaba con rica tradición italiana" (99).

${ }^{10}$ Stanton (135) proporciona esta versión del soneto de Bernardo Tasso:

Mentre che l'aureo crin v'ondeggia intorno

a l'amplia fronte con leggiadro errore;

mentre che di vermiglio e bel colore

vi fa la primavera il volto adorno;

mentre che v'apre il ciel più chiaro il giorno,

cogliete, ô giovenette il vago fiore

de vostri più dolci anni; e con amore

state sovente in lieto e bel soggiorno.

Verrà poi'l verno, che di bianca neve

suol i poggi vestir, coprir la rosa,

e le piagge tornar aride e meste.

Cogliete ah stolte, il fior; ah siate preste,

ché fugaci son l'hore, e'l tempo lieve,

e veloce a la fin corre ogni cosa. 
Garcilaso acudió también a la Oda de Horacio a Ligurino (IV, X), y, como era inevitable, tuvo presente el 'Collige, virgo, rosas' de Ausonio (99).

Stanton añade que Garcilaso además de imitar "la belleza formal del soneto italiano .... también vertebró su estructura floja y amorfa, dinamizó e hizo más concreto el lenguaje y las imágenes" (135-136).

En el caso de Góngora, Carballo Picazo, criticando al precursor afirma que: "El soneto de Tasso describe demasiado, no tiene la incisiva comparación de Góngora, la arquitectura recta, el artificio del paralelismo y de la correlación, las enumeraciones desnudas y, sobre todo, el tétrico final" (383). Gerli tiene similar criterio: defiende la originalidad del texto gongorino pero reconoce su dependencia temática respecto del de Tasso. Pero ésta no es la única deuda del cordobés. Si aceptamos que su poema fue escrito en 1582 (Ciplijauskaité 230), fecha posterior al año de la edición de Garcilaso comentada por Herrera, ${ }^{1}$ parece razonable la hipótesis propuesta por Calcraft de que la composición de Góngora fue escrita imitando y emulando a ambos, Tasso y Garcilaso:

In treating the classical theme of carpe diem, Góngora was not only taking one of the most familiar concepts in literature as his starting-point, but also challenging comparison with several well-known Renaissance poets, among them Bernardo and Torquato Tasso, and of course the Spaniard who by now (1582) was also a classic, Garcilaso de la Vega. By dealing with this theme, therefore, Góngora elected both to show his knowledge of ancient and modern classics, and to try his skill before a public that was likely to be at least as knowledgeable as he of the antecedents of his work (332).

Aznar afirma lo mismo al señalar que el cordobés "emula deportivamente" al toledano (63).

Con referencia al soneto de Balbuena, la crítica, mucho menos generosa que con los peninsulares, no ha sido muy precisa. Carilla, de una manera apresurada, lo ha tipificado de "gongorista", ya que su "arquitectura es similar a uno de los más antiguos de Góngora" (34). Otros, me refiero a Alonso, han tenido el acierto de ubicar la fuente privilegiada, el texto de Tasso, pero no han ido más lejos que el comentario trivial y simplificatorio de que era una "traducción del italiano" (253). Por mi parte, considero que Balbuena es tan "original" como el castellano y el andaluz. Es más, estimo que su soneto es imitación de los de Tasso y Garcilaso y, quizás, del de Góngora, ${ }^{12}$ enriqueciendo esa cadena de referencialidades a la que se hizo mención en párrafos anteriores.

\footnotetext{
"Aznar se equivoca al proporcionar 1582 como el año de la edición comentada de la obra de Garcilaso hecha por Herrera (59). La mayoría de los críticos, Calcraft, 332; Carballo Picazo, 383; Vázquez, 36; etc., está de acuerdo que la edición de Herrera data de 1580 .

${ }^{12}$ El soneto gongorino, 1582, es anterior al de Balbuena, 1608. Sin embargo, de acuerdo a Rama, la circulación de los manuscritos de Góngora en Nueva España, donde residía Balbuena, empieza en 1613. Debido a esta distancia no se puede afirmar, tal cual lo hace Carilla, que el novohispano haya imitado al andaluz. Esta cautela es compartida por Alonso: "No hay motivos seguros para probar ni rechazar la imitación de Góngora por Balbuena" (241). La razón por la que admito la posibilidad de imitación de Góngora por Balbuena, es que éste realizó, en 1606, un viaje de estudios a la península
} 
Expresar que los tres sonetos dicen lo mismo no parece arriesgado; creo, sin embargo, que difieren en la coincidencia y poseen significados diversos. En la península ibérica, desde épocas medievales, el tópico del carpe diem constituía un instrumento retórico persuasivo con finalidad amatoria. ${ }^{13}$ Así parecen utilizarlo los poetas objeto de este estudio. Pero hay algo más. En ellos el carpe diem es, en esencia, aunque con diferencia de grado, una reflexión sobre la cronofagia; es decir, la destrucción de los elementos, incluido el tiempo, por el incesante fluir de éste.

Garcilaso, en el último terceto de su poema, reflexiona en forma explícita sobre los efectos del paso del tiempo que, como agente destructivo tipificado por "edad ligera" ("tempo lieve" en el soneto de Tasso), exige un grado de concreción metafórica resuelto por referencias climático-estacionales. El elemento temporal funciona en torno a los semas "transcurso" (del tiempo) y "estación" (división metereológica del año).

La bisemia de la palabra "tiempo" es fundamental. Por un lado, hace posible la metaforización de la dama en términos "estacionales": la juventud se identifica a la primavera y la vejez al invierno, con sus respectivos atributos de belleza y decrepitud. Por otro, y quizá esto sea lo importante, el devenir del tiempo quiebra la identificación del transcurrir metereológico (dividido en ciclos de primavera e invierno), con la edad (tiempo cronológico o lineal) de la dama. En un primer instante su belleza coincide con la de la primavera y su rostro se asemeja a rosa y azucena. Más adelante (11-12), el enunciador, de manera omnisciente y tomando en cuenta la experiencia del cambio temporal, afirma con certeza que el invierno, sema implícito de nieve y viento helado, se instalará en la hermosura de la dama y la "marchitará". En este contexto, el "invierno" de la belleza femenina es un punto de no retorno en oposición al carácter cíclico del tiempo metereológico: la vejez concluye con la muerte, en tanto que al invierno, "vejez" del tiempo cíclico, le sigue la primavera y así en lo sucesivo.

La presencia de estos conceptos del tiempo, el lineal donde se encuentra la dama y el cíclico normador de la naturaleza, es vital porque su contraposición hace posible la efectividad del tema del carpe diem; pero sobre todo, el triunfo de lo cíclico sobre lo lineal. La "mudanza" de la "edad ligera", la "primavera" de la dama, es irreversible puesto que la belleza femenina será devorada por el paso de los años. Sucede lo contrario con la primavera, ya que ésta, la belleza de la naturaleza si se quiere, volverá otra vez en un nuevo ciclo no sujeto al efecto aniquilador del tiempo cronológico.

El soneto de Balbuena comparte hasta cierto punto la concepción del elemento temporal en los semas "transcurso" y "clima". Sin embargo, la reflexión sobre su función, en sus dos aspectos, se resuelve en el último verso. El paso de los años ya no está confinado a "mudar" todo por efecto de agentes externos, "viento helado" y "edad ligera", sino que es el propio tiempo el que influye para que éste, en ambos semas, fluya: "Si la edad pasa, el tiempo la apresura" (12). De modo que el tiempo cronológico o lineal, identificado con

(Rojas Garcidueñas 21). Allá pudo familiarizarse con la obra del cordobés. Tampoco se sabe sobre su correspondencia con literatos castellanos de la época que, entre 1582 y 1608 , pudieron haberle suplido el texto gongorino.

${ }^{13}$ En el Libro de buen amor, por ejemplo, Trotaconventos trata de persuadir a doña Endrina de amar a don Melón de la Uerta. Véanse las estrofas 725-765. 
edad, es subsumido por el tiempo (concepto absoluto en este contexto) que, a su vez, coincide (véase el último terceto) con la última serie del tiempo cíclico que se prolonga hasta el fin del tiempo, lineal y cíclico, donde hallan su "fin todas las cosas". Cada cosa a su tiempo y todas en conjunto.

En esa forma, el tratamiento del concepto temporal es más abstracto, complejo y radical que en el soneto de Garcilaso; y, paradójicamente, más preciso. Balbuena empieza con idéntica concepción de éste en sus dos vertientes: lineal y cíclico. Lo diferente es el final. Allí el tiempo lineal triunfa sobre el cíclico, ya que del mudar, del "marchitar", es decir, de un proceso de degeneración gradual y repetitivo, se pasa al "fin [de] todas las cosas" (14). En ese punto, ¿juicio final?, el tiempo, lineal y cíclico, se ha devorado a sí mismo. Esta idea del obispo poeta es coherente con la interpretación que la religión cristiana tiene del elemento temporal definido en función a un principio y un fin, ${ }^{14}$ concepto opuesto a la definición "pagana" que prioriza su aspecto cíclico. ${ }^{15}$

En el soneto de Góngora la reflexión sobre el tiempo es menos evidente que en los anteriores. El final, sin embargo, al igual que en el de Balbuena, asume características de destrucción total. La coincidencia no es casual. ${ }^{16} \mathrm{Al}$ fin y al cabo Góngora tenía fuertes tendencias religiosas que habrían influido en su idea sobre la naturaleza finita del elemento temporal. Lo que extraña, por lo menos en apariencia, es que no se notan referencias precisas al tiempo. La única alusión está implícita en "edad dorada"; frase que, con todas las resonancias mitológicas que expresa, hace mención al tiempo en su transcurso lineal. "Edad dorada", en el contexto del soneto, es un punto vago ubicado en el pasado; es decir, en el tiempo cronológico. Y por tanto, irreversible y condenado a pasar para siempre. Es por esto que los atributos de la belleza femenina degeneran en un proceso continuo, no por efectos metafóricos externos identificados con el tiempo cíclico, primavera e invierno, (tal el caso de Garcilaso y Balbuena), sino por el paso inexorable del tiempo lineal: "se vuelva" (13).

Un aspecto interesante del soneto gongorino, y que lo diferencia de los demás, es el de la metaforización en torno no al tiempo climático y sí en un plano mineralógico. La "edad dorada" con sus atributos de "oro", lilio, clavel, cristal luciente" (11, énfasis mío) se deteriora en "plata", un metal menos noble. La progresiva degradación continúa hasta desembocar en una aniquilación total hecha posible por el transcurso del tiempo lineal.

${ }^{14}$ En La Santa Biblia abundan las referencias al tiempo cuyo fin está próximo: "tiempo del fin" (Daniel 8.19), "hasta que los tiempos de los gentiles se cumplan" (Lucas 21.24), "el tiempo está cerca" (Lucas 21.28), "tiempo corto"(1 Corintios 7.29), "ya es el último tiempo"(1 Juan 2.18), "Bienaventurado el que lee, y los que oyen las palabras de esta profecía, y guardan las cosas en ellas escritas; porque el tiempo está cerca" (Apocalipsis 1.3), "el diablo ha descendido a vosotros con gran ira, sabiendo que tiene poco tiempo" (Apocalipsis 12.12), "Y me dijo: No selles las palabras de la profecía de este libro, porque el tiempo está cerca" (Apocalipsis 22.10).

${ }^{15}$ Se habla de una concepción de tiempo "cristiano" en el sentido de una línea recta inaugurada el momento de la creación y que va a concluir con el juicio final. Por su parte, la concepción "pagana" prioriza el tiempo cíclico condenado a repetirse bajo nuevos avatares. Una discusión más precisa de estos temas puede encontrarse en el trabajo de Manfred Kerkhoff y en Los hijos del limo de Octavio Paz.

${ }^{16}$ La obsesión por la fugacidad del tiempo y, aunque menos evidente, por el tiempo en sí, es uno de los temas privilegiados del Barroco, período al que pertenecen Góngora y Balbuena. 
El proceso de deterioración es importante por dos razones. Primero, prefigura el final nihilista del soneto permitiendo al poeta reconocer la existencia de un código preexistente, el tiempo que marchita la belleza, y al cual le añade algo distinto (la destrucción total): "no sólo en plata o víola troncada/ se vuelva, mas tú y ello juntamente/ en tierra, en humo, en polvo, en sombra, en nada" (12-14). Segundo, facilita pasar de un contexto de semas estacionales abstractos (tiempo cíclico), a un sistema de semas telúricos precisos (tiempo lineal). Por ejemplo, en el primer caso, la primavera hace referencia a juventud y el invierno a vejez. En el segundo, los semas de oro son juventud y hermosura, los de plata vejez y decrepitud, el de tierra polvo, y el de nada la aniquilación total.

Del análisis anterior se infiere que una diferencia notable entre estos sonetos radica en el código organizativo de los rasgos de la hermosura de la dama. Es cierto que todos priorizan el retrato canónico de la época y empiezan con la descripción de la cabeza en términos metafóricos más o menos lexicalizados, ${ }^{17}$ pero se apartan al seguir subcódigos de independencia relativa. Tal el caso del empleo de semas organizativos en función de metáforas de flores y metales preciosos para describir la hermosura femenina. Garcilaso y Góngora, al igual que su modelo, utilizan un eje tripartito de semas: oro, color y luz (Terracini 346).

Tasso: ORO (aureo crin); COLOR (vermiglio e bel colore); LUZ (più chiaro il giorno).

Garcilaso: ORO (cabello escogido “en la vena del oro"); COLOR(rosa, azucena); LUZ (clara luz).

Góngora: ORO (cabello “oro bruñido”); COLOR (lilio, clavel); LUZ (luciente cristal, cristal luciente).

Balbuena, en cambio, estructura el código petrarquista de las metáforas de flores y metales preciosos en torno a los semas oro, color y juventud.

ORO (cabello “oro ensortijado"); COLOR (rosas, clavel, marfil); JUVENTUD (limpia y tersa frente, fresco viento, tiernas rosas, primavera).

El uso del sema juventud, en vez del de luz, lo aparta de sus fuentes y contribuye a que el soneto, tal como se verá después, posea una lógica poética interna más efectiva que el de los demás en cuanto al tratamiento de los efectos del tiempo sobre la hermosura.

En cuanto a las referencias intertextuales de estas composiciones, me refiero a las de Garcilaso y Góngora, existen muchos trabajos que las contrastan para ilustrar diferencias y coincidencias. No sucede lo mismo con la de Balbuena. Por esta razón doy prioridad a su interrelación con las de Tasso y Garcilaso sin perder de vista un posible parentesco con la de Góngora.

El soneto de Balbuena no sigue un modelo sino varios. Es por esto que su filiación no es directa y sí más compleja de lo que parece. Mi punto de partida es un hecho conocido en la época. Colombí-Monguió afirma que "cuantos habían leído los Comentarios del

\footnotetext{
${ }^{17}$ En El ingenioso hidalgo don Quijote de la Mancha, Cervantes, describiendo a Dulcinea, critica los rasgos que los poetas asignan a sus damas: "su hermosura, sobrehumana, pues en ella se vienen a hacer verdaderos todos los imposibles y quiméricos atributos de belleza que los poetas dan a sus damas: que sus cabellos son oro, su frente campos elíseos, sus cejas arcos del cielo, sus ojos soles, sus mejillas rosas, sus labios corales, perlas sus dientes, alabastro su cuello, mármol su pecho, marfil sus manos, su blancura nieve ..." (171-172).
} 
Brocense a Garcilaso de la Vega sabían que este soneto de Bernardo Tasso era el modelo del célebre 'En tanto que de rosa y azucena'" (228). Además de este dato, se conocían las opiniones poco favorables de Herrera al último verso garcilasiano. ${ }^{18}$ Es posible que Góngora y Balbuena hayan tenido en cuenta esas críticas; y por ello, trataron de mejorar, es decir, superar al soneto de Garcilaso imitando a éste y a su fuente más inmediata (Tasso).

En otras palabras, Góngora y Balbuena emularon al toledano. El concepto aemulatio es muy importante en la poética de la época. Su finalidad es imitar a un clásico para obtener la victoria sobre éste: "Se trata naturalmente de imitar un modelo para superarlo, o como decía Erasmo, "la meta de la imitación es la similitud; la de la emulación, la victoria"" (Colombí-Monguió 231). Y una de las condiciones de la emulación es que el "imitador" no disimule su modelo; es más, éste debe ser identificado con facilidad para que todos reconozcan el triunfo de quien lo emula. Con estas precisiones tiene más sentido la afirmación de Aznar de que Góngora habría emulado "deportivamente" a Garcilaso. Actitud semejante pudo haber impulsado a Balbuena. La hipótesis cobra relieve si se tiene en cuenta su condición de prelado insigne, ${ }^{19}$ ya que como tal, nada más alejado de su voluntad que escribir versos profanos incitando al goce de un presente efímero encarnado en la belleza de una mujer. ${ }^{20}$ Creo que por esto, Balbuena, y quizás también Góngora, es más objetivo que Garcilaso en la utilización de la belleza femenina con una finalidad artística antes que "amatoria".

La primera palabra anafórica de los cuartetos de Balbuena, "mientras", denuncia, al igual que en los de Góngora, su procedencia italiana (mentre). ${ }^{21}$ La fuente se confirma con "la limpia y tersa frente" (amplia fronte) y el "cabello de oro ensortijado" (aureo crin). El parecido aunque profundo es diferente de una mera traducción. Lo que Balbuena hace es preconizar el subtexto italiano sobre el castellano. Esto se nota porque invierte el orden de aparición de los sustantivos "frente" y "cabello", además de enriquecer la adjetivación de ambos. Por otra parte, el "cabello de oro ensortijado" no constituye una traducción de "aureo crin". Es más, la referencia puede encontrarse en "hebras de oro ensortijado" o "Cual d'oro era el cabello ensortijado", líneas que pertenecen a Francisco de Terrazas, ${ }^{22}$ poeta novohispano contemporáneo de Balbuena, y a Fernando de Herrera. ${ }^{23}$ No obstante el parecido de estos versos, el sujeto poético de Terrazas y Herrera es muy diferente. El

\footnotetext{
${ }^{18}$ El juicio de Herrera es tajante: "este es lánguido i casi muerto verso, i mui plebeyo modo de hablar; fue común falta en aquella edad no solo de los nuestros, pero de los Toscanos, acabar el soneto, no con la fuerza i espíritu de los cuarteles, sino floxa, desmayadamente" (Citado por Carballo Picazo $383)$.

${ }^{19}$ Zavala informa que en 1608, año de la publicación del Siglo de oroen las selvas de Erifile, Balbuena era abad de Jamaica. Años más tarde, 1624, ascendió al obispado de Puerto Rico (805).

${ }^{20}$ La afirmación cobra relevancia si se tiene en cuenta que para la ideología tradicional de la iglesia, en esa época, toda mujer atractiva representaba un peligro.

${ }^{21}$ Garcilaso, al emplear el término "En tanto", recurre a un sinónimo de "mientras" y "entre tanto" que, de acuerdo al Diccionario de autoridades, tienen las siguientes acepciones:

"MIENTRAS. adv. de tiempo, que significa lo mismo que Interin, ó Entre tanto" (565).

"Entre tanto. Modo adverbial, que significa lo mismo que En tanto ..." (516).

${ }_{22}^{2}$ Ver Méndez Plancarte 22.

${ }^{23}$ Ver Herrera 462-463.
} 
primero se refiere a una dama y Herrera a Febo, divinidad griega famosa por su "áurea cabellera". Esta frase y sus variantes, cabello de oro o cabello áureo, son metáforas triviales repetidas desde tiempos de Homero. Al contrario, "cabello de oro ensortijado" (énfasis mío) es una metáfora poética. ${ }^{24}$ Primero, se tiene que concebir, además de "oro", "oro ensortijado", frase que en sí misma constituye una metáfora porque el metal, en su estado natural, no se encuentra ensortijado, adjetivo que refuerza el sentido figurado del verso. Con este procedimiento el ingenioso obispo se salva de caer en la metáfora lexicalizada de "cabello de oro" u otra variante de ésta.

En el mismo cuarteto se lee que el pelo de la mujer vuela "marañado", alusión directa a la línea garcilacesca de "el viento mueve, esparce y desordena". Pero el cabello, por lo demás referencia obligada, deja de ser un adorno independiente de la cabeza de la mujer y constituye parte integral de ésta, ya que se lo menciona en relación a la "tersa frente". Actitud connotada por el hecho de que vuela "sobre las tiernas rosas del oriente" (4). Es decir, sobre el rostro juvenil y bello de la dama. ${ }^{25}$ Por otra parte, la cita anterior es una alusión concreta al primer verso del castellano ("de rosa y azucena"); puesto que en el soneto de Tasso, aunque se habla de "vermiglio e bel colore" (3), no existe referencia directa a metáfora de flor alguna. Bastarían estas precisiones para descalificar la opinión de que el poema de Balbuena es una "traducción del italiano".

La frase "tiernas rosas del oriente", aparte de introducir el texto garcilasiano, no deja de tener cierta audacia poética inexistente, en cuanto al tratamiento de las metáforas de flores, en el toledano. Garcilaso habla de "rosa y azucena", flores que a pesar de su riqueza en evocar semas de belleza y distinción moral (véase el trabajo de Stanton), se quedan cortas ante la adjetivación más precisa, y al mismo tiempo ambigua, de la frase de Balbuena que, con este giro, prefigura a un poeta moderno.

La añadidura de semas en el verso cuarto, en oposición a "rosas", juega un papel trascendental. El futuro obispo de Puerto Rico, al agregar el sema "tiernas", y en esto sigo la teoría del Grupo de Liège, pasa de una significación a otra. Las "tiernas rosas", además de aludir a flores que significan las mejillas femeninas, enriquecen el lenguaje figurado proporcionando al sustantivo rosas una denotación humana reforzada por la referencialidad de lugar "del oriente". Éste es un caso de metasemema en el que se "pervierte" el sentido normal de un sema. Los posibles semas de "rosa", en el contexto del verso, aluden al color de las mejillas de la dama, pero también a su belleza, distinción, nobleza, etc. (En el caso de Garcilaso los semas de "rosa" se reducen a los labios; y los de "azucena" a las mejillas). ${ }^{26}$ Asimismo, la adición del sema "tiernas" precisa, en tanto referencia cronológica, que se trata de una mujer joven y casta; y en esta última acepción la función del término es muy parecida

\footnotetext{
${ }^{24}$ Para Ricoeur: "The difference between trivial metaphor and poetic metaphor is not that one can be paraphrased and the other not, but that the paraphrase of the latter is without end" (188).

${ }^{25} \mathrm{La}$ insistencia en describir el rostro de la dama podría ser criticada desde una perspectiva feminista. Sin embargo, en el código de Petrarca, privilegiado por estos poetas, la belleza facial es signo de gracia e inteligencia. Consúltese la importancia del petrarquismo y sus normas descriptivas en los trabajos de Cropper, Cruz, Durling, Freccero, Fucilla y Vickers.

${ }^{26}$ El conjunto "rosa y azucena" también puede referirse al vaivén del blanco y del rojo en las mejillas de la mujer.
} 
al de "azucena" en Garcilaso. Las palabras "del oriente”, por su parte, complican el material metafórico. No es muy difícil visualizar a una rosa tierna pero ¿cómo son las "tiernas rosas del oriente"?

El sema "oriente" que denota un lugar impreciso, exótico y poco conocido en la época, ${ }^{27}$ personifica con ambigua precisión a la dama de Balbuena quien, con este giro, se aleja de sus dos modelos. Equiparar las mejillas de una mujer a una rosa, o a cualquier otra flor, no es una "metáfora viva" y sí una catacresis. Lo metafórico consiste en evocar la juventud ("tierna") y el exotismo ("del oriente") de la mujer a partir de sus mejillas ("rosas"). Estas connotaciones no pueden ser logradas con la simple utilización de "rosa", término que con dificultad evoca de manera simultánea semas de juventud y exotismo. Pero al concebir a una rosa "tierna" y "del oriente" se entra al terreno del metasemema y del metalogismo unidos en una misma expresión. Lo metalógico consiste en aceptar que una rosa, la flor más manoseada por la poesía, pueda ser joven y exótica. Por otra parte, la audacia poética de Balbuena resalta por la ausencia de los términos "gesto", "frente", "rostro" o "mejillas", utilizados implícita y explícitamente por sus modelos. Con esta estrategia, añadidura y ausencia de semas, Balbuena enriquece el lenguaje figurado de su poema.

En el inicio del segundo cuarteto se vuelve al subtexto italiano con la palabra "mientras" (mentre), vocablo de uso obligado para comenzar los cuartetos. ${ }^{28}$ El novohispano desarrolla sus versos instalando la primavera (juventud) en el rostro de la joven. La presencia primaveral, que en Góngora equivale a "edad dorada", es un motivo común de estas composiciones. Lo que difiere es la oportunidad en que es introducida. Tasso lo hace de prisa, en el verso final del primer cuarteto, y Garcilaso al inicio del primer terceto. Balbuena, por su parte, insiste en la presencia de la primavera y de inmediato invita a su goce resaltando sus excelencias a través de la imagen difícilmente visualizable del "clavel, sobre marfil sentado" (6). La insistencia tiene más sentido con la inserción del "coged" sujeto a la acción del tiempo; y sobre todo, con su caracterización de algo veloz, fugaz y que "no se siente" (8). El eclesiástico y poeta, una vez más, sigue y se aleja de sus modelos. Es cierto que Tasso, en el segundo cuarteto, introduce "cogliete", pero esta acción además de prematura, no posee la efectividad poética de la de Balbuena (véase el trabajo de ColombíMonguió).

Garcilaso y Góngora eligen el primer terceto para lanzar sus respectivos "coged" y "goza" como una receta ante el poder destructivo del tiempo sin mediar una definición precisa de éste. Balbuena, no satisfecho con esos tratamientos, altera la estructura de ambos; $\mathrm{y}$, antes de hablar de las consecuencias del elemento temporal, lo define en referencia a su función rectora y efecto inmediato: "que el tiempo corre, huye y no se siente" (8) ${ }^{29}$ Verso magistral que podría ser calificado de redundante por la utilización de "corre" y "huye".

\footnotetext{
${ }^{27}$ Algunos textos de la época hablan de Egipto, Arabia, Persia, etc. Sin embargo, no me ha sido posible ubicar una referencia específica a "rosas del oriente".

${ }^{28}$ No deja de llamar la atención que el término anafórico "mientras" es la palabra más utilizada en estos sonetos: tres en Tasso, dos en Garcilaso, en su variante "en tanto," cuatro en Góngora y dos en Balbuena.

${ }^{29}$ De acuerdo a Colombí-Monguió, acá se puede manifestar que Balbuena hace referencia al tempus fugit de Petrarca que, a través de este concepto, podría ser un subtexto no activo del novohispano.
} 
Pero correr y huir son dos verbos diferentes. No siempre se corre cuando se huye y mucho menos se huye cuando se corre. Este juego de acciones posee un complejo sentido poético porque el agente que los realiza es el tiempo que al "correr" se aleja de todos los seres, y al "huir" sin ser sentido, ¿dónde?, establece una distancia mucho más profunda que la mensurable en términos físicos.

$\mathrm{Al}$ no haber retardado la mención del tiempo con su atributo de un fluir incesante, Balbuena estructura sus tercetos con más unidad temática y formal que la de sus arquetipos. En el primer terceto, por ejemplo, formula una pregunta retórica inexistente en los otros textos. ${ }^{30}$ El terceto es también una respuesta implícita al último verso del segundo cuarteto. Pero su función no concluye ahí. La reflexión se prolonga sobre el inexistente "fruto" que obtendrá la dama de su belleza marchita por el invierno. Con la mención del "fruto" Balbuena se aparta del soneto de Tasso y se aproxima al del toledano que hace referencia al "dulce fruto" de la "alegre primavera" de la dama (9-10). Sin embargo, cuando el novohispano hace mención al "invierno" (10), el subtexto activo es el soneto del italiano (9) antes que el de Garcilaso, quien prefiere utilizar la expresión "el tiempo airado" (10) para encanecer "la hermosa cumbre" (11). Esta interpretación refuerza la idea de que Balbuena entreteje sus arquetipos en una especie de contrapunteo que se resuelve en el eclecticismo del undécimo verso. En éste se refiere a "la lumbre de oro" y a "las encarnadas rosas". Es decir, Garcilaso y su modelo están presentes en la línea de Balbuena. El toledano habla de que "la hermosa cumbre" (cuyos cabellos se escogieron en la "vena del oro") se cubrirá de nieve y Tasso manifiesta que la nieve va a "coprir la rosa". El novohispano, maestro en imitar y emular, viste de nieve la cabeza cantada por Garcilaso de la Vega y la rosa ofrecida por Bernardo Tasso. Más allá de distribuir con simetría los subtextos que sigue, el primer terceto es una especie de puente que permite empezar el segundo con una respuesta magnífica sobre el papel del tiempo sin necesidad de transición alguna.

En el último terceto de Balbuena los subtextos siguen entrelazados, pero su conclusión es más tajante y eficaz que la de ellos. El novohispano, que ya preparó el terreno desde el primer terceto, insiste en el fluir incesante del tiempo (12) que culmina en "hallan y tienen fin todas las cosas" (14). "Hallan" y "tienen fin" parecen significar lo mismo. No. Para Balbuena el sentido de todas las cosas es "hallar" el fin del futuro; es decir, la conclusión del tiempo lineal, o si se quiere, el día del juicio final. ${ }^{31}$ Una vez logrado esto, las cosas no pueden seguir siendo, han alcanzado o hallado su meta; y por lo tanto, "tienen fin" en ese punto donde el tiempo, "en su curso breve" (13), ha concluido.

\footnotetext{
${ }^{30}$ Por la forma en que utiliza la pregunta retórica, se me ocurre aventurar que el prelado novohispano podría haber estado pensando en la siguiente estrofa de otro hombre de la iglesia: ¿Qué provecho vos tien vestir ese negro paño, andar avergonzada e con mucho sossaño? Señora, dexa[t] duelo e fazet el cabo de año; nunca la golondrina mejor consejó ogaño

(Libro de buen amor 79. Estrofa 762).

${ }^{31}$ Dadas las connotaciones religiosas y morales del término se podría argüir que no sería consistente que Balbuena recomendara a la dama que cogiera "las flores y alegrías del prado". Sin embargo, el que escribe no es un individuo en funciones religiosas sino un poeta que "imita" y trata de superar a sus modelos.
} 
El último terceto de Tasso, en cambio, empieza con una transición débil que reintroduce el "cogliete" ya expuesto en el quinto verso. Es cierto que la conclusión de su soneto es muy parecida a la de Balbuena: "e veloce a la fin corre ogni cosa". Nótese, sin embargo, que el verso final balbuenesco es más complejo. En el de Tasso no se enfatiza el fin del tiempo como tal sino el de las cosas que, luego de haber alcanzado ese punto, no se sabe qué es de ellas.

Garcilaso, desde Herrera (ver nota 18) hasta críticos más recientes (Lapesa, Stanton, etc.), ha sido escoriado por el final poco feliz de su soneto. No es éste el lugar ni el momento para repetir esos comentarios. Sólo añado que su concepción del tiempo es menos "cristiana" y mucho más "pagana" que la de Balbuena. El tiempo no concluye para Garcilaso. Su fin es el de "mudar" todo, (y con esto otorga el triunfo a la fase cíclica sobre la lineal), sin mencionar en ningún momento la aniquilación total que emparenta a Tasso con Góngora y Balbuena.

El análisis hecho en este ensayo muestra que en los sonetos estudiados hay uno o más juicios estéticos genéricos. Por ejemplo, la exhortación al goce de la belleza juvenil; y de una manera más sutil, las ideas sobre la naturaleza del tiempo. En la primera actitud subyace la filosofía cirenaica que funda la felicidad sobre el placer. En la segunda, disfrutar un instante preciso, desde una perspectiva poética, equivale a eternizarse en la fugacidad del tiempo. El tema es común pero su tratamiento distinto. Esto se nota en la concepción del elemento temporal y en la forma organizativa del mismo, aspectos que determinan que estos artefactos literarios digan otra cosa utilizando los mismos recursos poéticos.

En una época en la que todos se imitaban más o menos todo, mal puede hablarse de "traducción" cuando se analiza un texto en continuo diálogo con otros, que a su vez, provienen de la misma fuente. Es por esto que la composición de Balbuena, que podría ser tipificada de soneto-sinfonía, es claramente imitativa y emulativa, pero ¿de quién? No hay una respuesta definitiva y sí muchas interpretaciones. La mía hace referencia a la intertextualidad de su poema con los de Tasso y Garcilaso, y hasta cierto punto, con el de Góngora. Teniendo en cuenta estas expresiones, decir que tal o cual es superior a otro constituye un acto voluntarista donde se ejercita la subjetividad de una lectura. La poesía, si se quiere emplear términos cuantitativos, es "algo más" que un torneo estético y "algo menos" que una disciplina científica (pienso en las matemáticas, la poesía de la eternidad). De modo que cualquier juicio de valor, derivado del análisis contrastivo, no pasa de ser una aproximación para comprender estos textos tan fascinantes como misteriosos.

Lo extraño de estos sonetos, aunque comprensible como tópico, es que a pesar de la distancia geográfica y cronológica que los separa, cantan a la misma dama; o mejor dicho, a los mismos labios, mejillas, cuello, frente y cabello. ${ }^{32}$ Una vez más las sutilezas de la poesía, con toda su originalidad y belleza, son insuficientes y artificiales para (re)velar el

\footnotetext{
32 Terracini, en el caso de Góngora, expresa que éste, a diferencia de Garcilaso, Tasso y otros poetas de la época, no desarticula a la dama: "A la mujer ya no se la alude metafóricamente (oro, flores, cristal/marfil), ni se la descompone metonímicamente en una serie de rasgos (cabello, frente, labio, cuello); se la denota directamente como totalidad de la persona: tú (y ello juntamente)" (348). Cierto, pero esta concepción está en función a la lógica interna del soneto. El final exige denotar a la dama como "sujeto total" y no descompuesto.
} 
ser de una persona. Queda, sin embargo, el consuelo de que, por lo menos hasta ahora, han vencido al tiempo.

\section{OBRas CITADAS}

Alonso, Dámaso. Góngora y el Polifemo. Madrid: Gredos, 1960.

Aznar A., Eduardo. "Clásico y Barroco (dos sonetos del clasicismo español)". Homenaje al profesor Antonio Vilanova. Vol. I. Marta C. Carbonell, ed. Barcelona: Universidad de Barcelona, 1989. 57-74.

Blecua, José Manuel, ed. Poesía de la Edad de Oro. I Renacimiento. Madrid: Castalia, 1984.

Calcraft, R.P. "The carpe diem Sonnets of Garcilaso and Góngora". The Modern Language Review 76/2 (1981): 332-337.

Carilla, Emilio. El gongorismo en América. Buenos Aires: Facultad de Filología y Letras de la Universidad de Buenos Aires, 1946.

Carballo Picazo, Alfredo. "El soneto 'Mientras por competir con tu cabello', de Góngora". Revista de Filología Española XLVII (1964): 379-398.

Cervantes y Saavedra, Miguel de. El ingenioso hidalgo don Quijote de la Mancha. Juan Bautista Avalle-Arce, ed. Madrid: Editorial Alhambra, 1978.

Ciplijauskaité, Biruté, ed. Luis de Góngora. Sonetos completos. Madrid: Castalia, 1985.

Colombí-Monguió, Alicia de. "Estrategias imitativas en el Siglo de Oro de Bernardo de Balbuena". Bulletin of Hispanic Studies. LXVI/3 (1989): 227-239.

Cropper, Elizabeth. "On Beautiful Women, Parmigianino, Petrarchismo, and the Vernacular Style". The Art Bulletin 58 (1976): 374-394.

Cruz, Anne J. Imitación y transformación. El petrarquismo en la poesía de Boscán y Garcilaso de la Vega. Amsterdam/Philadelphia: John Benjamins Publishing Company, 1988.

Durling, Robert M. "Petrarch's 'Giovene donna sotto un verde lauro"”. Modern Language Notes 86 (1971): 1-20.

Freccero, John. "The Fig Tree and the Laurel: Petrarch's Poetics". Diacritics 5.1 (Spring 1975): $34-40$.

Fucilla, Joseph G. Estudios sobre el petrarquismo en España. Madrid: Consejo Superior de Investigaciones Científicas, 1960.

Gerli, E. Michael. "Más allá del carpe diem: el soneto "Mientras por competir con tu cabello' de Luis de Góngora". Estudios en homenaje a Enrique Ruiz-Fornells. Juan Fernández J., José J. Labrador H. y L. Teresa Valdivieso, eds. Erie, Pennsylvania: ALDEEU, 1990. 255-258.

Góngora, Luis de. Sonetos completos. Biruté Ciplijauskaité, ed. Madrid: Castalia, 1985.

Herrera, Fernando de. Poesías. Victoriano Roncero López, ed. Madrid: Castalia, 1992.

Kerkhoff, Manfred. "El tiempo sagrado". Diálogos XV, 35 (1980): 37-59.

Kristeva, Julia. Le texte du roman. París: Mouton, 1970.

Sémiotiké, recherches pour une sémanalyse. París: Seuil, 1969.

Lapesa, Rafael. "Sobre algunos sonetos de Garcilaso". La poesía de Garcilaso. Elías Rivers, ed. Barcelona: Editorial Ariel, 1974. 91-102. 
Méndez Plancarte, Alfonso, ed. Poetas novohispanos. Primer siglo 1521-1621. México: Ediciones de la Universidad Nacional Autónoma, 1942.

Paz, Octavio. Los hijos del limo. Barcelona: Seix Barral, 1974.

Las peras del olmo. México: Imprenta Universitaria, 1957.

Pigman, George W., III. "Versions of Imitation in the Renaissance". Renaissance Quarterly 33 (1980): 1-32.

Rama, Ángel. "Fundación del manierismo hispanoamericano por Bernardo de Balbuena". University of Dayton Review 16/2 (1983): 13-22.

Real Academia Española, ed. Diccionario de autoridades. 3 vols. D-Ñ, edición facsímil. Madrid: Gredos, 1963.

Ricoeur, Paul. The Rule of Metaphor. Toronto: University of Toronto Press, 1991.

Rivers, Elías, ed. La poesia de Garcilaso: ensayos críticos. Barcelona: Editorial Ariel, 1974.

Rojas Garcidueñas, José. Bernardo de Balbuena. La vida y la obra. México: Imprenta Universitaria, 1958.

Ruiz, Juan. Libro de buen amor. Anthony N. Zahareas, ed. Madison: The Hispanic Seminary of Medieval Studies, Ltd., 1989.

Sociedad Bíblica Americana, ed. La Santa Biblia. Antiguo y Nuevo Testamento. Antigua versión de Casiodoro de Reina (1569), revisada por Cipriano de Valera (1602). Nueva York, 1960.

Stanton, Edward F. "En tanto que de rosa y azucena ..." Historia y crítica de la literatura española. Siglos de Oro: Renacimiento. Francisco Rico, ed. Barcelona: Grijalbo, 1980. 132-137.

Terracini, Lore. "Cristal', no 'marfil', en 'Mientras por competir con tu cabello"”. Homenaje a Ana María Barrenechea. Lia Schwartz Lerner e Isaías Lerner, eds. Madrid: Castalia, 1984. 341-353.

Vázquez, Manuel Ángel. Poesía y poética de Fernando de Herrera. Madrid: Narcea S.A. de Ediciones, 1983.

Vickers, Nancy J. "The Body Re-membered. Petrarchan Lyric and the Strategies of Description". Mimesis. From Mirror to Method, Augustine to Descartes. John D. Lyons and Stephen G. Nichols, Jr., eds. Hanover and London: University Press of New England, 1982. 100-109.

"Diana Described: Scattered Woman and Scattered Rhyme". Critical Inquiry 8 (1981): 265-279.

Zavala, Iris M. "Metáforas epistemológicas coloniales: 'En breve cárcel'”. Estudios de folklore y literatura dedicados a Mercedes Díaz Roig. Beatriz Garza Cuarón e Yvette Jiménez de Báez, eds. México: El Colegio de México, 1992. 803-815. 